\title{
Metastable beta Ti-Nb-Mo alloys with improved corrosion resistance in saline solution
}

\author{
R. Chelariu ${ }^{1}$, G. Bolat ${ }^{2}$, J. Izquierdo ${ }^{3}$, D. Mareci $^{2}$, D.M. Gordin ${ }^{4}$, T. Gloriant ${ }^{4}$, R.M. Souto ${ }^{3,5}$ \\ 1 The "Gheorghe Asachi" Technical University of Iasi, Faculty of Materials Science and \\ Engineering, 41 Prof. dr. doc. D. Mangeron St., 700050, Iasi, Romania \\ 2 The "Gheorghe Asachi" Technical University of Iasi, Faculty of Chemical Engineering and \\ Environmental Protection, 73 Prof. dr. doc. D. Mangeron St., 700050, Iasi, Romania \\ ${ }^{3}$ Department of Chemistry, University of La Laguna, E-38205 La Laguna, Tenerife, Canary Islands, \\ Spain \\ ${ }^{4}$ INSA Rennes, UMR CNRS 6226 Institut des Sciences Chimiques de Rennes / Chimie Métallurgie, \\ 20 avenue des Buttes de Coësmes, 35043 Rennes Cedex, France \\ ${ }^{5}$ University of La Laguna, Instituto Universitario de Materiales y Nanotecnologías, 38200 La \\ Laguna (Tenerife, Canary Islands), Spain
}

\begin{abstract}
:
The present study explores the microstructural characteristics and electrochemical responses of four metastable beta Ti-Nb-Mo alloys for biomedical implantation. They were synthesized by the cold crucible levitation melting technique, and compositions were selected to keep the molybdenum equivalency close to $12 \mathrm{wt} \%$ Moeq. For the sake of comparison, Ti12Mo was also investigated. Microstructural characterization reveals that all the alloys are $\beta$ (body-centred cubic structure), and the surface is composed by $\beta$ equiaxial grains with dimensions in the range of tens to hundreds $\mu \mathrm{m}$. The corrosion resistance (potentiodynamic polarization and electrochemical impedance spectroscopy) of the alloys was determined in $0.9 \mathrm{wt} \% \mathrm{NaCl}$ saline solution at $25{ }^{\circ} \mathrm{C}$. The materials spontaneously form a passivating oxide film on their surface, and they are stable for polarizations up to $+1.0 \mathrm{~V}_{\text {SCE. }}$. No evidence of localized breakdown of the oxide layers is found for polarizations more positive than those encountered in the human body. The passive layers show dielectric characteristics, and the wide frequency ranges displaying capacitive characteristics occur for both higher niobium contents in the alloy and longer exposures to the saline solution. The insulating characteristics of the oxide-covered surfaces were investigated by scanning electrochemical microscopy operated in the feedback mode, using ferrocene-methanol as redox mediator. Both $z$ approach curves and amperometric images were taken over the surface of the samples both at their open circuit potential and polarized. It has been found that Ti8Nb10Mo and Ti16Nb8Mo exhibit the lowest activity towards electron transfer. The new Ti-Nb-Mo ternary alloys are regarded to be potential candidates for biomedical application on the basis of both their microstructural characteristics and their corrosion resistance in saline solution with chloride content equivalent to body fluids.
\end{abstract}

Keywords: Ti-Nb-Mo alloys; corrosion resistance; Ti based surface oxides; saline solution; biomaterial application. 


\section{Introduction}

The development and characterization of new Ti-based alloys containing non-toxic elements has become the topic of investigation [1-3] due to awareness of systemic effects of corrosion from the materials commonly employed in the manufacture of biomedical implants for bone and teeth replacement [4,5], including reports of metallosis and necrosis [6-8]. In the search for new materials, $\beta$-Ti type alloys are regarded to be the most promising ones. Thus, new $\beta$-Ti alloys using $\mathrm{Nb}, \mathrm{Ta}, \mathrm{Zr}$ and Mo as alloying elements ( $\beta$-stabilizer elements) have been developed [9-18].

The aim of this study is to elaborate and to characterize new alloys compositions in the ternary Ti-Mo-Nb system with the objective to design new biomedical metastable beta Ti-based alloys with improved corrosion resistance. As alloying element, niobium is well known to be very good to resist against corrosion in simulated body fluid and presents an excellent biocompatibility $[19,20]$. The use of molybdenum is still controversial [21] but some studies have demonstrated adequate mechanical compatibility and good cyto-compatibility of Ti-alloys containing molybdenum such as Ti-Mo, Ti-Mo-Ta or Ti-Mo-Zr-Fe [22-25]. The advantage of using Mo is that this element has strong $\beta$-stabilizing properties on titanium alloys in comparison with $\mathrm{Nb}$, Ta or $\mathrm{Zr}$ elements.

In this work, four new Ti-Mo-Nb alloy compositions were produced in which the molybdenum equivalency was fixed at around $12 \mathrm{wt} \%$ Moeq. Ti12Mo was also synthesized in the same manner to serve as reference. The microstructures of the alloys were characterized using optical microscopy and X-ray diffraction, whereas their corrosion behaviour was investigated in saline solution (namely, $0.9 \mathrm{wt} \% \mathrm{NaCl}$ ). The human body fluids are aqueous electrochemical media containing the equivalent to $0.9 \mathrm{wt} \% \mathrm{NaCl}$ and their $\mathrm{pH}$ is homeostatically regulated at 7.4 [26,27]. The corrosion of implantable metallic materials remains an important issue concerning its biocompatibility and long-term stability of implants. The in vivo degradation of implants leads to the loss of its functionality and integrity, and corrosion products induces local and/or systemic effects [27-29].

\section{Material and methods}

\subsection{Alloy synthesis}

The five following alloy compositions (given in wt\%) were synthesized in this study: Ti12Mo, Ti10Mo8Nb, Ti8Mo16Nb, Ti6Mo24Nb, and Ti4Mo32Nb. Each alloy possesses a molybdenum equivalency composition fixed at ca. $12 \mathrm{wt} \%$ Moeq. They were synthesized by the cold crucible levitation melting (CCLM) technique in an induction furnace (Fives Celes, Lautenbach, France) under a pure Ar atmosphere, which was introduced after several cycles of high vacuum pumping. After solidification, the alloys were heat treated at $950{ }^{\circ} \mathrm{C}$ for 20 hours (annealed in the $\beta$ - 
phase domain) in order to homogenize the microstructure due to the thermal gradient occurring during solidification, and then water quenched. The ingots were cold rolled to $90 \%$ in thickness and machined to obtain tensile test specimens and corrosion test samples. After this mechanical treatment, all samples were solution treated at $850{ }^{\circ} \mathrm{C}$ for 30 minutes and water quenched. The aim of this treatment was to restore a fully recrystallized metastable $\beta$ microstructure from the cold-rolled state.

\subsection{Alloy characterization methods}

To check the nominal chemical composition of each alloy after fabrication, EDX analyses were carried out in a JEOL JSM 6400 scanning electron microscope operating at $20 \mathrm{kV}$.

The crystalline structure of the recrystallized alloys was characterized by X-ray diffraction (XRD) at ambient temperature using a Philips PW 1830/00 (Eindhoven, The Netherlands) diffractometer (CuK $\alpha_{1}$ radiation, $1.5406 \AA ̊$ wavelength).

The microstructures of the alloys were characterized by optical microscopy using a Leica DM RM system (Wetzlar, Germany). Prior to optical imaging, the samples were first mechanically abraded using a sequence of silicon carbide abrasive papers followed by a final polishing step with a colloidal silica suspension (particle size: $50 \mathrm{~nm}$ ). Next, the samples were cleaned in alcohol and distilled water using an ultrasonic bath, and finally etched in a solution containing 5 wt\% $\mathrm{HNO}_{3}, 5$ wt\% $\mathrm{HF}$ and the balance in $\mathrm{H}_{2} \mathrm{O}$. Samples were observed under polarized light to enhance the phase contrast.

\subsection{Electrochemical measurements}

The test specimens were placed in a glass corrosion flow cell kit (C145/170, Radiometer, France), which was filled with naturally-aerated $0.9 \mathrm{wt} \% \mathrm{NaCl}$ solution [30]. A saturated calomel electrode was used as the reference electrode, and a platinum coil as the counter electrode. The potentials in this paper are reported versus the saturated calomel electrode (SCE). All potentials in this work are given with respect to SCE. The temperature of the electrochemical cell was maintained at $25 \pm 0.1{ }^{\circ} \mathrm{C}$. Though the intra-oral temperature fluctuates on ingestion of hot or cold food and beverage, it can be reasonably approximated in experiments by setting the environmental temperature at $25^{\circ} \mathrm{C}$ [31].

Electrochemical measurements were performed using a potentiostat model PARSTAT 4000 (Princeton Applied Research, NJ, USA). The instrument was controlled by a personal computer and VersaStudio software. Prior to testing, the working electrodes were mechanically abraded using 
emery paper up to 2000 grit, next polished with $0.3 \mu \mathrm{m}$ alumina suspension, ultrasonically cleaned in acetone and deionized water, and finally dried in open air.

Potentiodynamic polarization and electrochemical impedance spectroscopy (EIS) methods were employed to characterize the corrosion behaviour of these new titanium-based alloys. The potentiodynamic polarization tests were initiated after $1 \mathrm{~h}$ immersion of the samples in the saline solution, when the open circuit potential acquired a stable value. The tests were conducted by scanning the potential, at the rate of $0.5 \mathrm{mV} \mathrm{s}^{-1}$, from $-1.0 \mathrm{VSCE}$ up to $+1.0 \mathrm{VSCE}$, followed by potential reversal down to $+0.5 \mathrm{VsCE}$ was attained, in order to explore the occurrence of pitting. From the measured potentiodynamic polarization curves, the zero current potential $\left(E_{\text {corr }}\right)$, the corrosion current density $\left(j_{\text {corr }}\right)$, and the passive current density $\left(j_{\text {pass }}\right)$ were determined.

Electrochemical impedance spectra were measured over a frequency range extending from $100 \mathrm{kHz}$ to $10 \mathrm{mHz}$ using a $10 \mathrm{mV}$ amplitude AC voltage signal. The EIS tests were recorded at the open circuit potential developed by the samples after 10 minutes, 1 hour, and 24 hours of immersion in the saline solution. EIS tests were obtained to evaluate the characteristics of passive films formed on the surface of the alloys under investigation. Analysis of the spectra was performed in terms of equivalent circuit (EC) fitting using ZSimpWin software.

All electrochemical tests were repeated three times to ensure reproducibility of the measurements.

\subsection{Scanning electrochemical microscopy (SECM)}

A high-resolution SECM equipment supplied by Sensolytics (Bochum, Germany), was employed for spatially-resolved characterization of the electrochemical reactivity of the TiNbMo alloys. The instrument was built around a PalmSens (Utrecht, The Netherlands) electrochemical interface, all controlled with a personal computer. The alloy specimens were either tested at their open circuit potentials spontaneously developed in the saline solution, or polarized using the bipotentiostat built in the electrochemical interface. The specimens were mounted horizontally facing upwards at the bottom of a cell made of polytetrafluoroethene, which was equipped with an $\mathrm{Ag} / \mathrm{AgCl} /(3 \mathrm{M}) \mathrm{KCl}$ reference electrode and a platinum counter electrode. For the sake of consistency, potentials were subsequently referred to the standard calomel electrode by taking in account the potential difference between the two electrodes. The electrochemical cell was located inside a Faraday cage. Tip microelectrodes were made from $10 \mu \mathrm{m}$ dia. platinum wires sealed in glass. $0.5 \mathrm{mM}$ ferrocene-methanol was added to the $0.9 \mathrm{wt} \% \mathrm{NaCl}$ solution to act as electrochemical mediator at the tip. To enable the oxidation of ferrocene-methanol the tip was kept at a constant 
potential of $+0.46 \mathrm{~V}_{\text {SCE }}$ [32]. The micromanipulator stand of the SECM instrument was used to hold the microelectrode in place. The operating tip distance over the sample for SECM imaging was established by slowly approaching the surface of the alloy specimen with the tip and simultaneously recording the measured current at the microelectrode vs. $z$ displacement (i.e., z-approach curve). In our experiments the microelectrode was either stopped when the measured current decreased to 30\% of the steady-state value in the bulk of the electrolyte, or when a current peak was detected while approaching the surface, and indication of mixed positive and negative feedback behaviours. Subsequently, the tip was withdrawn $10 \mu \mathrm{m}$ from the sample surface, and images were obtained by scanning the tip parallel to the sample surface (i.e., constant height operation). SECM images were recorded rastering an area of $250 \mu \mathrm{m}$ x $250 \mu \mathrm{m}$ using a scan rate of $30 \mu \mathrm{m} \mathrm{s}^{-1}$. Temperature control was not performed, and data were recorded at ambient temperature (ca. $22 \pm 3{ }^{\circ} \mathrm{C}$ )

\section{Results and discussion}

\subsection{Microstructural characterization}

The chemical compositions of the etched Ti-based alloys were confirmed by EDS analysis, and each nominal composition was obtained with less than $0.5 \mathrm{wt} \%$ allowance, which corresponds to the precision of the EDS method.

The five alloys were found to be $\beta$ (body-centred cubic structure) by X-ray diffraction as shown in Figure 1. Indeed, all the peaks in the diffractograms peak can unambiguously indexed according to this crystallographic structure, and the corresponding diffracted planes are indicated in the plot. The occurrence of some additional though very small peaks is observed for the alloys rich in Mo (i.e., Ti12Mo, Ti10Mo8Nb, and Ti8Mo16Nb). In fact, the presence of hexagonal $\omega_{\text {ath }}$ phase nanoprecipitates (dimension less than $5 \mathrm{~nm}$ ) in metastable $\beta$ Ti-Mo based alloys, which are formed by displaced transformation during quenching, has been reported for a long time [33-35].

\section{Figure 1}

A typical example of the recrystallized microstructure found by optical microscopy on the considered alloys is presented in Figure 2. The micrograph actually shows the microstructure of the Ti10Mo8Nb alloy, but it is very similar to those observed for the other alloys. $\beta$ equiaxial grains with dimensions in the range of tens to hundreds $\mu \mathrm{m}$ are observed, in good agreement with the XRD observations.

\section{Figure 2}




\subsection{Electrochemical characterization: corrosion resistance}

Figure 3 depicts the potentiodynamic polarization curves measured for the various alloys during immersion in naturally-aerated saline solution at $25^{\circ} \mathrm{C}$. All samples exhibited similar features, characteristic of materials exhibiting a passive behaviour in the test environment, though there is no evidence of an active-passive transition. This feature indicates that the oxide film spontaneously developed at the surface of the alloys upon immersion in the test electrolyte exhibits passivation characteristics. Additionally, the potential excursion up to $+1.0 \mathrm{~V}_{\mathrm{SCE}}$, a value significantly higher than the polarizations ever measured in the human body [36], does not show the breakdown of the passive films related to the initiation of localized corrosion processes in any of the alloys. Tafel analysis delivered values for the corrosion potentials ( $\left.E_{\text {corr }}\right)$ and the corrosion current densities $(j$ corr $)$ of the materials, values of the passive current densities ( $\left.j_{\text {pass }}\right)$ were evaluated from the current plateaus at potentials more positive than $0 \mathrm{VSCE}$. The corresponding average values for these parameters are listed in Table 1. The values of these corrosion parameters support that the decrease in the molybdenum content, and the subsequent increase in niobium content though made in such a way that the equivalent molybdenum content could be maintained constant, effectively leads to the

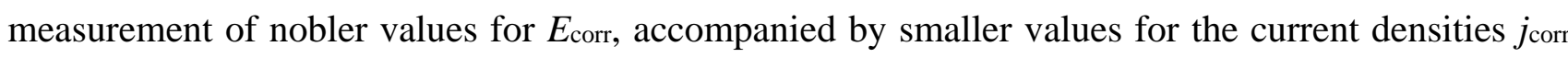

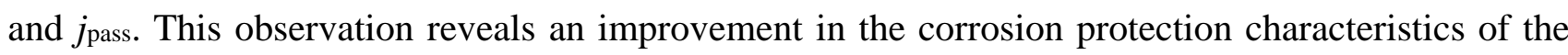
alloys by increasing the content of niobium [37]. The same observation was found by Atapour et al. [38] in their comparison of the corrosion behaviours of Ti6Al4V, Ti13Mo7Zr3Fe (both $(\alpha+\beta)$ and metastable $\beta$ condition), and Ti35Nb7Zr5Ta alloys performed in $0.9 \mathrm{wt} \% \mathrm{NaCl}$ solution at $37^{\circ} \mathrm{C}$. They reported smaller $j_{\text {corr }}$ values for Ti13Mo7Zr3Fe (metastable $\beta$ condition) and Ti35Nb7Zr5Ta as compared to those for Ti6Al4V and Ti13Mo7Zr3Fe $((\alpha+\beta)$ condition), whereas Ti35Nb7Zr5Ta showed the smallest passivation current density $\left(j_{\text {pass }}\right)$. On the other hand, the current density values determined by Zheng et al. [39] for Ti-16 at\% Nb-(4.0, 4.5, 5.0) at\% Sn (approximately Ti-25 wt\% $\mathrm{Nb}-(8,9,10) \mathrm{wt} \% \mathrm{Sn}$ ) are very close to those found in our work (namely $0.1 \leq j$ corr $\leq 0.3 \mu \mathrm{A} \mathrm{cm} \mathrm{cm}^{-2}$, and $4.3 \leq j_{\text {pass }} \leq 10.0 \mu \mathrm{A} \mathrm{cm}^{-2}$ ), though the corresponding values of $E_{\text {corr }}$ were slightly more positive (in the range $-0.2>E_{\text {corr }}>-0.4 \mathrm{VSCE}$ ). A similar trend in the values of the corrosion parameters was found for Ti-22 at\% Nb-(0, 2, 4, 6) at\% Hf (approximately Ti- (35, 34, 32, 31) wt\% Nb-(0, 6, 11, 16) $\mathrm{wt} \% \mathrm{Hf}$ ) in $0.9 \mathrm{wt} \% \mathrm{NaCl}$ neutral solution maintained at $37^{\circ} \mathrm{C}$ [40]. In this case, the corresponding

data were: $0.633 \geq j_{\text {corr }} \geq 0.052 \mu \mathrm{A} \mathrm{cm} \mathrm{cm}^{-2}, 8.0 \geq j_{\text {pass }} \geq 5.5 \mathrm{~cm}^{-2}$, and $-0.2>E_{\text {corr }}>-0.4$ VSCE. No breakdown potential was identified in the potentiodynamic polarization curves for the tested potential range, and no pits were observed for the retrieved samples. 


\section{Figure 3}

Table 1

In order to obtain further information on the characteristics of the passive films and the nature of the electrochemical processes at the interface, EIS tests were performed. The EIS data of the alloys measured at three different immersion times in the test solution are presented in Figures 4-6 in the form of Bode plots (impedance modulus and phase angle versus frequency diagrams). In all cases, only one time constant is observed in the spectra, and they could be satisfactorily simulated using the simplified Randles' circuit shown in Figure 7, which has been previously employed to describe the impedance behaviour of various titanium-based alloys exposed to saline and physiological solutions [29,40-46]. This equivalent circuit assumes that the corrosion of the passive metal is hindered by an oxide film that acts as a barrier-type compact layer. The parameters $R_{\mathrm{pL}}$ and $Q_{\mathrm{pL}}$ describe the properties of the passive films formed on these metallic materials, respectively the resistance and capacitance of the compact oxide layers, whereas $R_{\text {sol }}$ stands for the solution resistance of the test electrolyte. The use of a constant phase element (CPE, $Q$ ) was required to account for the distributed relaxation feature commonly exhibited by the passive films formed on titanium-based alloys [47]. It arises from surface inhomogeneities (roughness and defects) present at the microscopic level [27,41]. The impedance parameters determined from fitting of the $R_{\mathrm{sol}}\left(R_{\mathrm{pL}} Q_{\mathrm{pL}}\right)$ equivalent circuit to the EIS data are given in Table 2. The fitting quality of the experimental EIS spectra to the model was established from the chi-squared $\left(\chi^{2}\right)$ values, in the order of $10^{-4}$, indicating the good agreement between experimental and simulated data that is also observed in Figures 4-6.

\section{Figure 4}

\section{Figure 5}

\section{Figure 6}

\section{Figure 7}

\section{Table 2}

From the inspection of the Bode plots, it is observed that the impedance characteristics of the system in the high frequency range are exclusively determined by the resistance of the electrolyte. 
That is, the phase angle drops to zero degrees whereas the impedance modulus tends to ca. $60 \Omega \mathrm{cm}^{2}$. This value of the solution resistance $\left(R_{\mathrm{sol}}\right)$ is almost half of that previously reported by Wang et al. in the same electrolyte [40]. In the medium and low frequency ranges, the Bode-phase plots exhibit a plateau with angles close to $-80^{\circ}$, whereas the values of the impedance modulus varied linearly with the frequency presenting slopes close to -0.9. These features are characteristic of passive films presenting a highly capacitive behaviour $[40,48,49]$. This capacitive behaviour extends over a wider frequency range as the alloys are exposed to the test electrolyte for longer exposures, confirming the improvement of the barrier characteristics of the passive film formed on the Ti-Nb-Mo alloys in this electrolytic environment. Additionally, the reported capacitive behaviour of passive films is more evident as the content of $\mathrm{Nb}$ increases and content of Mo decreases in the materials. In summary, the data presented in Table 2 show an enhancement of the corrosion resistance of the alloys with the increase of both the $\mathrm{Nb}$ content in the alloy and the immersion time to the saline solution. And these values of the impedance parameters $R_{\mathrm{pL}}, n$, and $Q_{\mathrm{pL}}$ are close to those previously reported for Ti-22 at\% Nb-(0, 2, 4, 6) at\% Hf (approximately Ti-(35, 34, 32, 31) wt\% Nb-(0, 6, 11, 16) wt\% Hf) in 0.9 wt\% $\mathrm{NaCl}$ neutral solution [40].

\subsection{Scanning microelectrochemical characterization: surface reactivity of the passive films}

SECM measurements were conduces as both vertical z-approach curves and 2D grid scans. In both cases, various randomly distributed portions of the exposed surface of the alloys were considered, in order to get a fair representation of the electrochemical behaviour of the material at the micrometer scale. Tip potential was set at $+0.46 V_{\text {SCE }}$ to ensure diffusional control for the reversible oxidation of ferrocenemethanol, a chemical that acted as the redox mediator. The experimental sequence consisted in firstly measuring the $z$-approach curves at four different locations of the surface, by bringing the tip from the bulk electrolyte towards the surface while measuring the faradaic current flowing at the tip for ferrocene-methanol oxidation. This procedure also allowed correcting any eventual tilt of the substrate occurring during assembling of the small microelectrochemical cell used for the SECM measurements. Next, the tip was retracted to a tipsubstrate distance equal to the tip diameter $(a=10 \mu \mathrm{m})$ to measure electrochemical activity maps at constant height over a $250 \mu \mathrm{m}$ x $250 \mu \mathrm{m}$ area. Surface activity towards electron transfer reactions was evidenced by higher tip current values while scanning than in the bulk of the electrolyte, resulting from the capacity of the surface region to donate one electron to the ferrocinium ion generated at the tip. 
Figure 8 shows typical z-approach curves measured shortly after immersion of the five alloys in the test solution containing ferrocene-methanol. Normalized current and distance values have been employed for easy comparison of the results, so every current value is referred to the limiting current measured in bulk solution, and distances are referred to the diameter of the platinum microdisc. Alloy surfaces were kept unpolarized in the test solution during these measurements. It has been observed that the Ti12Mo surface presents the higher electron transfer rate, as evidenced by the big increase of the tip current when it approaches to the substrate (i.e., positive feedback behaviour). Thus, the passive layer spontaneously formed on the surface of TiMo under spontaneous open circuit potential conditions, maintains a rather high electrical conductivity and can operate as a source of electrons for the regeneration of ferrocene-methanol species from the ferrocinium ions generated at the tip. Redox mediator regeneration becomes more difficult when the tip approaches the surfaces of Ti8Nb10Mo and Ti16Nb8Mo instead, as evidenced by the onset of a mixed kinetic behaviour. That is, though the tip current initially increases while the tip approaches the surface from the bulk electrolyte blockage to diffusion of the redox mediator towards the tip by a somewhat insulating surface at small tip-substrate distances, leads to a final decrease of the tip current. It is shown that the passive layer is not an efficient electron donor for the reduction of ferrocinium. Finally, the two alloys with the highest niobium contents (i.e., Ti24Nb6Mo and Ti32Nb4Mo) show positive feedback behaviour, thus closer resembling the electrochemical behaviour found for Ti12Mo. These observations on the electrochemical activity of the alloys at the micrometer scale apparently contradict the average measurements based on EIS measurements. Impedance data showed a systematic growth of the corrosion resistance of the oxide films for increasing contents of niobium in the alloys (cf. Table 2), and this might be regarded to directly correlate to the susceptibility of the surfaces towards electron exchange. However, according to the SECM results in Figure 8, it seems that there is an optimum niobium content for the alloys, around 8 to $16 \mathrm{wt} \%$, if electron donation is to be avoided. Materials with the Higher niobium content are effectively more resistant towards corrosion, but their passive layers can still sustain electron transfer reactions at the surface. Considering also surface conductivity affects to the results obtained by SECM in this configuration, apparently the higher protective layers formed on the 24 and $32 \mathrm{wt} \%$ niobium containing alloys are less electrically-insulating than those for 8 and $16 \mathrm{wt} \%$ composition, although they provide a greater protection against corrosion in the saline solution.

\section{Figure 8}

The spatial distribution of electrochemical activity of the five alloys immersed in the saline solution was evaluated by recording SECM grid scans at constant height while the samples were 
both at their open circuit potentials and polarized at $-0.54,-0.24$ and +0.16 VSCE. Typical SECM images are given in Figures 9-11 for Ti12Mo, Ti8Nb10Mo and Ti16Nb8Mo, and Ti24Nb6Mo and Ti32Nb4Mo, respectively. In general, the current measured at the tip decreases as the potential of the substrates was set at more positive values. Therefore, the oxidized ferrocinium ion generated at the tip while scanning the alloys is no longer reduced to regenerate ferrocene-methanol at the surface of the alloys when more anodic potentials are applied to them. This is mainly due to the increase of the thickness of the passive layer when the potential increases. However, the magnitude of this effect differs from one material to another. As it can be seen in Figure 9, Ti12Mo is able to regenerate ferrocene-methanol at most of its surface when left at its spontaneous OCP yet clear heterogeneous behaviour is encountered. When potential is set at $-0.54 \mathrm{VSCE}$, normalized current values close to unitiy are observed. This indicates that the surface activity towards electron donation has decreased, yet the positive feedback effect almost compensates the diffusion blockage of the mediator produced by the small electrolyte volume comprised between the tip and the surface. At More positive potentials, namely -0.24 and $+0.16 \mathrm{VSCE}$, negative feedback behaviour dominates the response of the system. That is, diffusion blockage by a predominantly insulating surface is the main behaviour, and this effect is stronger at some distributed regions where the current depletion occurs in a bigger extent. Yet, the measurements at $+0.16 \mathrm{VSCE}$ must be taken with some caution, because the potential of the substrate is already positive enough that some oxidation of ferrocene-methanol may occur on the substrate. In that event, smaller tip currents would result from the competition between the substrate and the tip for the oxidation of ferrocenemethanol, and not exclusively from negative feedback properties of the surface.

\section{Figure 9}

\section{Figure 10}

\section{Figure 11}

Smaller tip currents related to feedback are found when the alloys contain niobium measured at their corresponding OCP values. It must be noticed that the SECM images depicted in Figure 10 have been plotted with a current range significantly narrower than those in Figure 9, because normalized current values higher than 1.15 are not found. A more electrochemically-homogeneous system is encountered while scanning these surfaces, especially when considering the Ti8Nb10Mo alloy. Again, the contribution of positive feedback is reduced when the substrate potential is set more positive. Yet, some differences between these two alloys may be deduced from the inspection of 
Figure 10C, that corresponds to the polarization value -0.24 VSCE. Significantly smaller tip current were observed in the case of Ti16Nb8Mo. This may suggest that the passive layer formed on this alloy during anodic polarization is more insulating, and this material may be regarded to be more corrosion resistant in an oxidizing environment.

Finally, images taken over the two high niobium containing alloys, presented in Figure 4, reproduce the same behaviour than that found for the Ti12Mo at the OCP and -0.54 V SCE. The more protective passive layer formed over Ti32Nb4Mo surface provides higher resistance towards electron transference in some areas, and this ability is maintained when biased at $-0.54 \mathrm{~V}_{\mathrm{SCE}}$, though this potential value is more negative than the spontaneous OCP of the material in the solution (cf. Table 1), but not cathodic enough to effectively reduce the oxide film formed on the surface of the alloy at its OCP while recording the z-approach curves and the SECM image given in Figure 11A. Passivated surfaces still participate in electron exchange for ferrocinium reduction when anodic polarization increases up to $-0.24 \mathrm{~V}_{\mathrm{SCE}}$, showing a heterogeneous distribution of the electrochemical activity, with some areas even leading to tip currents higher than those determined in the bulk solution. Finally, at +0.16 VSCE, normalized current values are smaller for the $24 \mathrm{wt} \%$ niobium alloy, whereas a distinctive heterogeneous distribution is observed for the material with the highest content of niobium (cf. Figure 11D). In this case, strong positive feedback behaviour was found at the beginning of the scan, possibly due to breakdown of the passive layer, and the current subsequently decreased rapidly due to passive layer rebuilding and the onset of competition effect towards ferrocene-methanol oxidation between the tip and the substrate.

\section{Conclusions}

All the investigated Ti-Nb-Mo alloys passivated spontaneously after immersion in $0.9 \mathrm{wt} \%$ $\mathrm{NaCl}$ and passive films have a capacitive behaviour analogously to Ti12Mo. Both corrosion and passive current densities decrease when the $\mathrm{Nb}$ content increases, a fact that indicates an improvement of the corrosion resistance of the materials in the saline solution. The analysis of EIS spectra has evidenced improvement of the protective characteristics of the passive films towards corrosion and metal dissolution by increasing the content of niobium in the alloy. The corrosion resistance provided by these oxide layers also improves with increasing immersion time in the test electrolyte, at least within the first 24 hours, consistent with thickening of the surface films. Dielectric properties of the surface films are yet greatly influenced by the niobium content, as demonstrated by scanning microelectrochemical characterization. In fact, electron transfer at the surface of the passivated alloys is hindered for niobium contents is in the range of 8 to $16 \mathrm{wt} \%$, and 
this behaviour is even more pronounced when positive potentials are applied to the substrate while immersed in the saline environment.

\section{Acknowledgments}

This work was supported by a grant of the Romanian National Authority for Scientific Research, CNCS-UEFISCDI, project number PN-II-ID-PCE-2011-3-0218, and by the Spanish Ministry of Economy and Competitiveness, and the European Regional Development Fund (Project No. CTQ2012-36787). A Grant awarded to J.I. by the Spanish Ministry of Education (Programa de Formación de Personal Investigador) is gratefully acknowledged.

\section{References}

[1] M. Long, H.J. Rack, Titanium alloys in total hip replacement, a materials science perspective, Biomaterials 19 (1998) 1621-1639.

[2] M. Niinomi, Mechanical properties of biomedical titanium alloys, Materials Science and Engineering A 243 (1998) 231-236.

[3] Y. Okazaki, S. Rao, Y. Ito, T. Tateishi, Corrosion resistance, mechanical properties, corrosion fatigue strength and cytocompatibility of new $\mathrm{Ti}$ alloys without $\mathrm{Al}$ and $\mathrm{V}$, Biomaterials 19 (1998) 1197-1215.

[4] A. Balamurugan, S. Rajeswari, G. Balossier, A.H.S. Rebelo, J.M.F. Ferreira, Corrosion aspects of metallic implants - An overview, Materials and Corrosion 59 (2008) 855-869.

[5] O. Addison, A.J. Davenport, R.J. Newport, S. Kalra, M. Monir, J.F.W. Mosselmans, D. Props, R.A. Martin, Do 'passive' medical titanium surfaces deteriorate in service in the absence of wear?, Journal of the Royal Society Interface 9 (2012) 3161-3164.

[6] C.P. Case, V.G. Langkamer, C. Jamec, M.R. Palmer, A.J. Kemp, P.F. Heap, L. Solomon, Widespread dissemination of metal debris from implants, Journal of Bone \& Joint Surgery 76B (1994) 701-712.

[7] I. Milošev, V. Antolič, A. Minovič, A. Cör, S. Herman, V. Pavlovčič, P. Campbell, Extensive metallosis and necrosis in failed prostheses with cemented titanium-alloy stems and ceramic heads, Journal of Bone \& Joint Surgery 82B (2000) 352-357.

[8] P. Korovessis, G. Petsinis, M. Repanti, T. Repantis, Metallosis after contemporary metal on metal total hip arthroplasty. Five to nine year follow up Journal of Bone \& Joint Surgery American 88 (2006) 1183-1191. 
[9] D. Kuroda, M. Niinomi, M. Morinaga, Y. Kato, T. Yashiro, Design and mechanical properties of new beta type titanium alloys for implants materials. Materials Science and Engineering A 243 (1998) 244-249.

[10] M. Niinomi, T. Hattori, K. Morikawa, T. Kasuga, A. Suzuki, H. Fukui, S. Niwa, Development of low rigidity $\beta$-type titanium alloy for biomedical applications. Materials Transactions 43 (2002) 2970-2977.

[11] D.M. Gordin, T. Gloriant. Gh. Nemtoi, R. Chelariu, N. Aelenei, A. Guillou, D. Ansel, Synthesis, structure and electrochemical behavior of a beta Ti-12Mo-5Ta alloy as new biomaterial, Materials Letters 59 (2005) 2936-2941.

[12] J. Qazi, H.J. Rack, Metastable beta titanium alloys for orthopedic applications, Advanced Engineering Materials 7 (2005) 993-998.

[13] L.M. Elias, S.G. Schneider, S. Schneider, H.M. Silva, F. Malvisi, Microstructural and mechanical characterization of biomedical Ti-Nb-Zr-(-Ta) alloys, Materials Science and Engineering A 432 (2006) 108-112.

[14] T. Gloriant, G. Texier, F. Prima, D. Laillé, D.M. Gordin, I. Thibon, D. Ansel, Synthesis and phase transformations of beta metastable Ti-based alloys containing biocompatible Ta, Mo and Fe beta-stabilizer elements, Advanced Engineering Materials 8 (2006) 961-965.

[15] N.T.C. Oliveira, S.R. Biaggio, P.A.P. Nascente, S. Piazza, C. Sunseri, F. Di Quarto, The effect of thickness on the composition of passive films on a Ti-50Zr at\% alloy, Electrochimica Acta 51 (2006) 3506-3515.

[16] M. Niinomi, Mechanical biocompatibilities of titanium alloys for biomedical applications, Journal of the Mechanical Behaviour of Biomedical Materials 1 (2008) 30-42.

[17] S.L. Assis, S. Wolynec, I. Costa, The electrochemical behaviour of Ti-13Nb-13Zr alloy in various solutions, Materials and Corrosion 59 (2008) 739-743.

[18] N.T.C. Oliveira, A.C. Guastaldi, Electrochemical stability and corrosion resistance of Ti-Mo alloys for biomedical applications, Acta Biomaterialia 5 (2009) 399-405.

[19] Y. Okazaki, S. Rao, T. Tateishi, Y. Ito, Cytocompatibility of various metal and development of new titanium alloys for medical implants, Materials Science and Engineering A 243 (1998) 250-256.

[20] H. Matsuno, A. Yokoyama, F. Watari, M. Uo, T. Kawasaki, Biocompatibility and osteogenesis of refractory metal implants Ti, Hf, Nb, Ta, Rh, Biomaterials 22 (2001) 1253-1262.

[21] E. Eisenbarth, D. Velten, M. Müller, R., Thull, J. Breme, Biocompatibility of beta-stabilizing elements of titanium alloys, Biomaterials 25 (2004) 5705-5713. 
[22] W.F. Ho, C.P. Ju, J.H. Chern Lin, Structure and properties of cast Ti-Mo alloys, Biomaterials 20 (1999) 2115-2122.

[23] L. Trentania, F. Pelilloa, F.C. Pavesia, L. Ceciliania, G. Cettab, A. Forlino, Evaluation of the TiMo12Zr6Fe2 alloy for orthopaedic implants: in vitro biocompatibility study by using primary human fibroblasts and osteoblasts, Biomaterials 23 (2002) 2863-2869.

[24] D.M. Gordin, T. Gloriant, G. Texier, I. Thibon, D. Ansel, J.L. Duval, M.D. Nagel, Development of a $\beta$-type Ti-12Mo-5Ta alloy for biomedical applications: cytocompatibility and metallurgical aspects, Journal of Materials Science: Materials in Medicine 15 (2004) 885-891.

[25] S. Nag, R. Banerjee, H.L. Fraser, Microstructural evolution and strengthening mechanisms in Ti-Nb-Zr-Ta, Ti-Mo-Zr-Fe and Ti-15Mo biocompatible alloys, Materials Science and Engineering C 25 (2005) 357-362.

[26] K.J. Bundy, Corrosion Testing in In Vivo Environments, in: R. Baboian (Ed.), Corrosion Tests and Standards: Application and Interpretation, ASTM, Philadelphia, PA, 2005, p. 500.

[27] S.L. Assis, S. Wolynec, I. Costa, Corrosion characterization of titanium alloys by electrochemical techniques, Electrochimica Acta 51 (2006) 1815-1819.

[28] A. Sargeant, T. Goswami, Hip implants: Paper V. Physiological effects, Materials Design 27 (2006) 287-307.

[29] C.V. Vidal, A.I. Muñoz, Electrochemical characterisation of biomedical alloys for surgical implants in simulated body fluids, Corrosion Science 50 (2008) 1954-1961.

[30] D. Mareci, I. Rusu, R. Chelariu, G. Bolat, C. Munteanu, D. Sutiman, R.M. Souto, Application of dynamic electrochemical impedance spectroscopy to the evaluation of the corrosion resistance of a historic bronze object in artificial acid rainwater, European Journal of Science and Theology 9 (2013) 189-199.

[31] G. Airoldi, G. Riva, M. Vanelli, V. Filippi, G. Garanttini, Oral environment temperature changes induced by cold/hot liquid intake, American Journal of Orthodontal and Dentofacial Orthopaedics 112 (1997) 58-63.

[32] G. Ciurescu, J. Izquierdo, J.J. Santana, D. Mareci, D. Sutiman, S. González, R.M. Souto, Characterization of the localized surface chemical activity of Ti-Mo and Ti-Ta alloys for biomedical applications using scanning electrochemical microscopy, International Journal of Electrochemical Science 7(2012) 7404-7424.

[33] M.J. Blackburn, J.C. Williams, Phase Transformations in Ti-Mo and Ti-V alloys, Transactions of The Metallurgical Society of the American Institute of Mining, Metallurgical and Petroleum Engineers 242 (1968) 2461-2469. 
[34] E. Sukedai, H. Hashimoto, M. Tomita, Investigation of omega-phase in Ti-Mo alloys by high resolution electron microscopy, image processing and dark-field methods, Philosophical Magazine A 64 (1991) 1201-1208.

[35] F. Prima, P. Vermaut, G. Texier, D. Ansel, T. Gloriant, Evidence of alpha-nanophase heterogeneous nucleation from omega particles in a beta-metastable Ti-based alloy by highresolution electron microscopy, Scripta Materialia 54 (2006) 645-648.

[36] T.P. Hoar, D.C. Mears, Corrosion-resistant alloys in chloride solutions: materials for surgical implants, Proceedings of the Royal Society London A 294 (1966) 486-510.

[37] Y.J. Bai, Y.B. Wang, Y. Cheng, F. Deng, Y.F. Zheng, S.C. Wei, Comparative study on the corrosion behavior of Ti-Nb and TMA alloys for dental application in various artificial solutions, Materials Science and Engineering C 31 (2011) 702-711.

[38] M. Atapour, A.L. Pilchak, G.S. Frankel, J.C. Williams, Corrosion behavior of $\beta$ titanium alloys for biomedical applications, Materials Science and Engineering C 31 (2011) 885-891.

[39] Y.F. Zheng, B.L. Wang, J.G. Wang, C. Li, L.C. Zhao, Corrosion behaviour of Ti-Nb-Sn shape memory alloys in different simulated body solutions, Materials Science and Engineering A 438-440 (2006) 891-895.

[40] B.L. Wang, Y.F. Zheng, L.C. Zhao, Effects of Hf content and immersion time on electrochemical behavior of biomedical Ti-22Nb-xHf alloys in $0.9 \% \mathrm{NaCl}$ solution, Materials and Corrosion 60 (2009) 330-335.

[41] X. Cheng, S.G. Roscoe, Corrosion behavior of titanium in the presence of calcium phosphate and serum proteins, Biomaterials 26 (2005) 7350-7356.

[42] S. Tamilselvi, N. Rajendran, Electrochemical studies on the stability and corrosion resistance of Ti-5Al-2Nb-1Ta alloy for biomedical applications, Trends in Biomaterials \& Artificial Organs 20 (2006) 49-52.

[43] S. Tamilselvi, R. Murugaraj, N. Rajendran, Electrochemical impedance spectroscopic studies of titanium and its alloys in saline medium, Materials and Corrosion 58 (2007) 113-120.

[44] S. Tamilselvi, N. Rajendran, In vitro corrosion behaviour of Ti-5Al-2Nb-1Ta alloy in Hanks solution, Materials and Corrosion 58 (2007) 285-289.

[45] S.E. Kim, J.H. Son, Y.T. Hyun, H.W. Jeong, Y.T. Lee, J.S. Song, J.H. Lee, Electrochemical corrosion of novel beta titanium alloys, Metals and Materials International 13 (2007) 151-154.

[46] M.E.P. Souza, L. Lima, C.R.P. Lima, C.A.C. Zavaglia, C.M.A. Freire, Effects of pH on the electrochemical behavior of titanium alloys for implant applications, Journal of Materials Science: Materials in Medicine 20 (2009) 549-552. 
[47] I.C. Lavos-Valereto, S. Wolynec, Electrochemical impedance spectroscopy characterization of passive film formed on implant Ti-6Al-7Nb alloy in Hank's solution, Journal of Materials Science: Materials in Medicine 15 (2004) 55-59.

[48] A.K. Shukla, R. Balasubramaniam, S. Bhargava, Effect of replacement of V by Fe and Nb on passive film behavior of $\mathrm{Ti}-6 \mathrm{Al}-4 \mathrm{~V}$ in simulated body fluid conditions, Journal of Alloys and Compounds 389 (2005) 144-152.

[49] S. Tamilselvi, V. Raman, N. Rajendran, Corrosion behaviour of Ti-6Al-7Nb and Ti-6Al-4V ELI alloys in the simulated body fluid solution by electrochemical impedance spectroscopy, Electrochimica Acta 52 (2006) 839-846.

Table 1. Corrosion parameters obtained from potentiodynamic polarization curves

\begin{tabular}{|c|c|c|c|}
\hline Alloy & $E_{\text {corr }}, \mathrm{V}_{\mathrm{SCE}}$ & $j_{\text {corr }, \mu \mathrm{A} / \mathrm{cm}^{2}}$ & jpass, $\mu \mathrm{A} / \mathrm{cm}^{2}$ \\
\hline Ti12Mo & -0.701 & 0.56 & 2.24 \\
\hline Ti8Nb10Mo & -0.640 & 0.43 & 2.32 \\
\hline Ti16Nb8Mo & -0.609 & 0.41 & 1.24 \\
\hline Ti24Nb6Mo & -0.514 & 0.38 & 0.86 \\
\hline Ti32Nb4Mo & -0.451 & 0.24 & 0.66 \\
\hline
\end{tabular}

Table 2. Values of passive film characteristics obtained by fitting the EIS data using $R_{s o l}\left(R_{p L} Q_{p L}\right)$ model of equivalent circuit (EC)

\begin{tabular}{|c|c|c|c|c|}
\hline Alloy & $\begin{array}{c}R_{\text {sol, }} \\
\Omega \mathrm{cm}^{2}\end{array}$ & $\begin{array}{c}Q_{p L}, \\
\mu \mathrm{S} \mathrm{cm}^{-2} \mathrm{~s}^{n} \\
\end{array}$ & $n$ & $\begin{array}{c}R_{p L}, \\
\mathrm{M} \Omega \mathrm{cm}^{2} \\
\end{array}$ \\
\hline \multicolumn{5}{|c|}{10 minutes immersion time } \\
\hline Ti12Mo & 59.6 & 0.13 & 0.82 & 0.58 \\
\hline Ti8Nb10Mo & 52.3 & 0.13 & 0.83 & 0.62 \\
\hline Ti16Nb8Mo & 66.1 & 0.12 & 0.83 & 0.75 \\
\hline Ti24Nb6Mo & 51.3 & 0.11 & 0.84 & 0.97 \\
\hline Ti32Nb4Mo & 61.9 & 0.11 & 0.85 & 1.10 \\
\hline \multicolumn{5}{|c|}{1 hour immersion time } \\
\hline Ti12Mo & 59.6 & 0.12 & 0.83 & 0.82 \\
\hline Ti8Nb10Mo & 52.3 & 0.12 & 0.83 & 0.95 \\
\hline Ti16Nb8Mo & 65.1 & 0.12 & 0.83 & 0.98 \\
\hline Ti24Nb6Mo & 54.3 & 0.11 & 0.84 & 1.20 \\
\hline Ti32Nb4Mo & 61.2 & 0.08 & 0.86 & 1.60 \\
\hline \multicolumn{5}{|c|}{24 hours immersion time } \\
\hline Ti12Mo & 60.4 & 0.11 & 0.84 & 0.94 \\
\hline Ti8Nb10Mo & 52.0 & 0.11 & 0.84 & 1.10 \\
\hline Ti16Nb8Mo & 66.3 & 0.11 & 0.84 & 1.10 \\
\hline Ti24Nb6Mo & 61.1 & 0.08 & 0.86 & 1.30 \\
\hline Ti32Nb4Mo & 62.2 & 0.07 & 0.86 & 1.90 \\
\hline
\end{tabular}




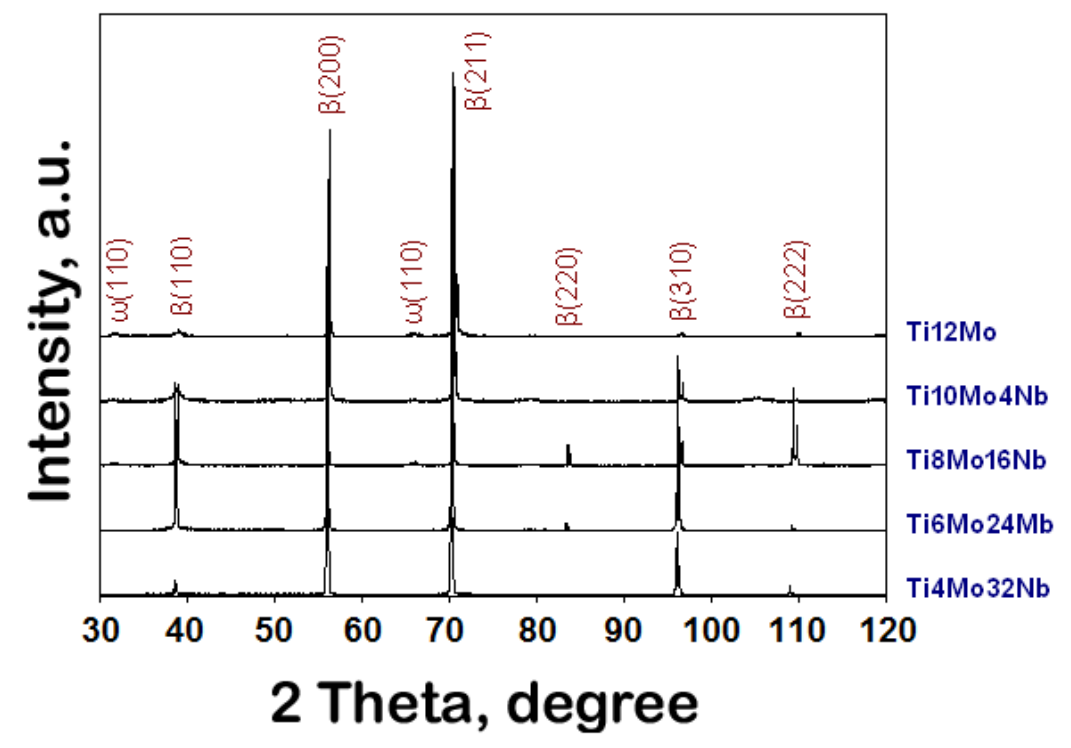

Figure 1.

XRD patterns of Ti12Mo and Ti-Mo-Nb alloys possessing a common molybdenum equivalency composition of ca. $12 \mathrm{wt} \%$ Moeq.

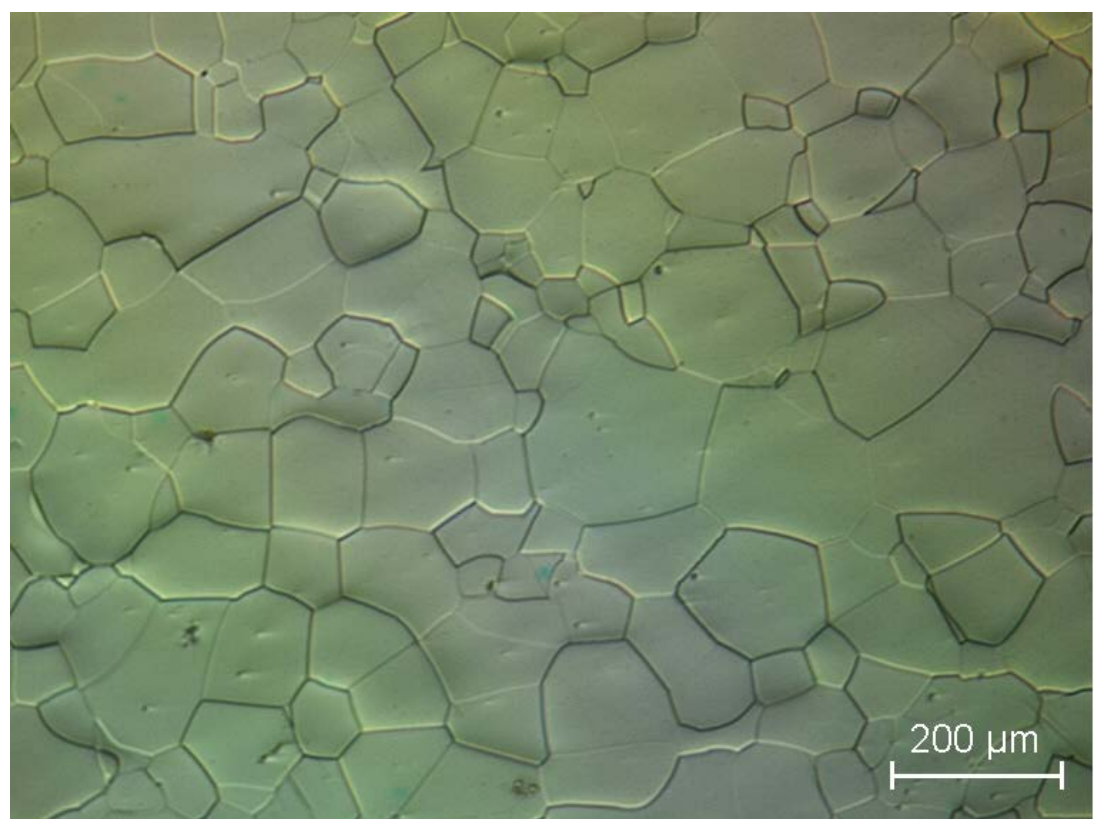

Figure 2.

Optical micrograph of the Ti10Mo8Nb alloy showing the recrystallized $\beta$-grain microstructure. 


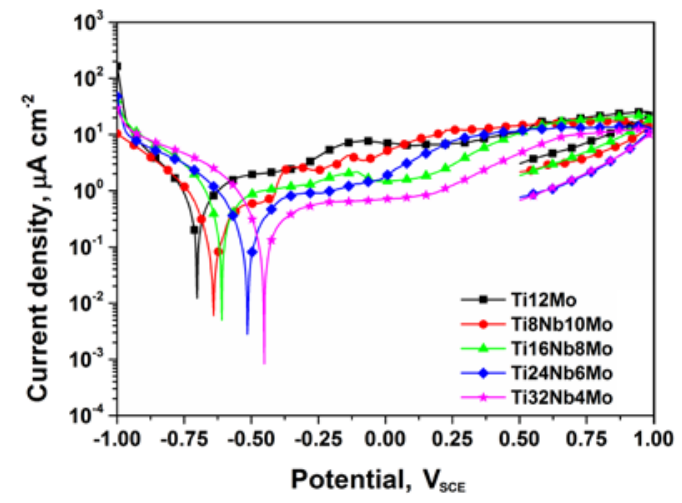

Figure 3.

Potentiodynamic polarization curves for the Ti12Mo and Ti-Mo-Nb alloys after $1 \mathrm{~h}$ immersion in 0.9 $\mathrm{NaCl}$ naturally-aerated solution at $25^{\circ} \mathrm{C}$. Scanning rate: $0.5 \mathrm{mV} \mathrm{s}^{-1}$.
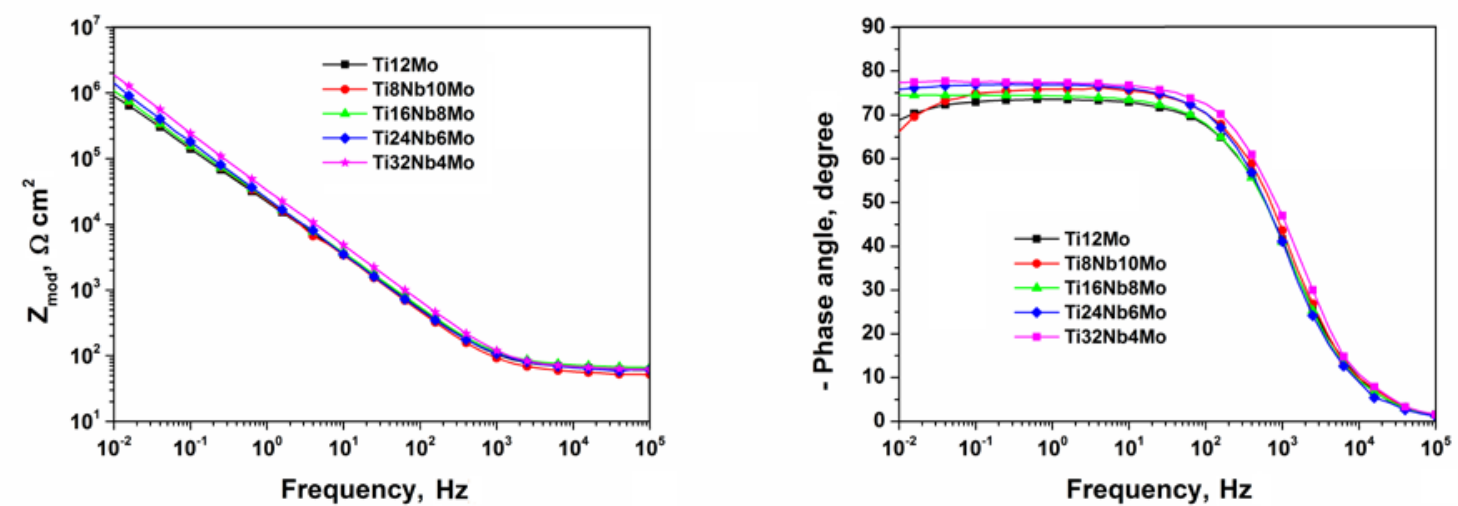

Figure 4.

Bode spectra for Ti12Mo and Ti-Mo-Nb alloys after 10 min in naturally aerated 0.9 wt\% $\mathrm{NaCl}$ solution at $25{ }^{\circ} \mathrm{C}$, measured at $E_{\text {corr. }}$. Measured (discrete points) and fitted (solid lines) data.
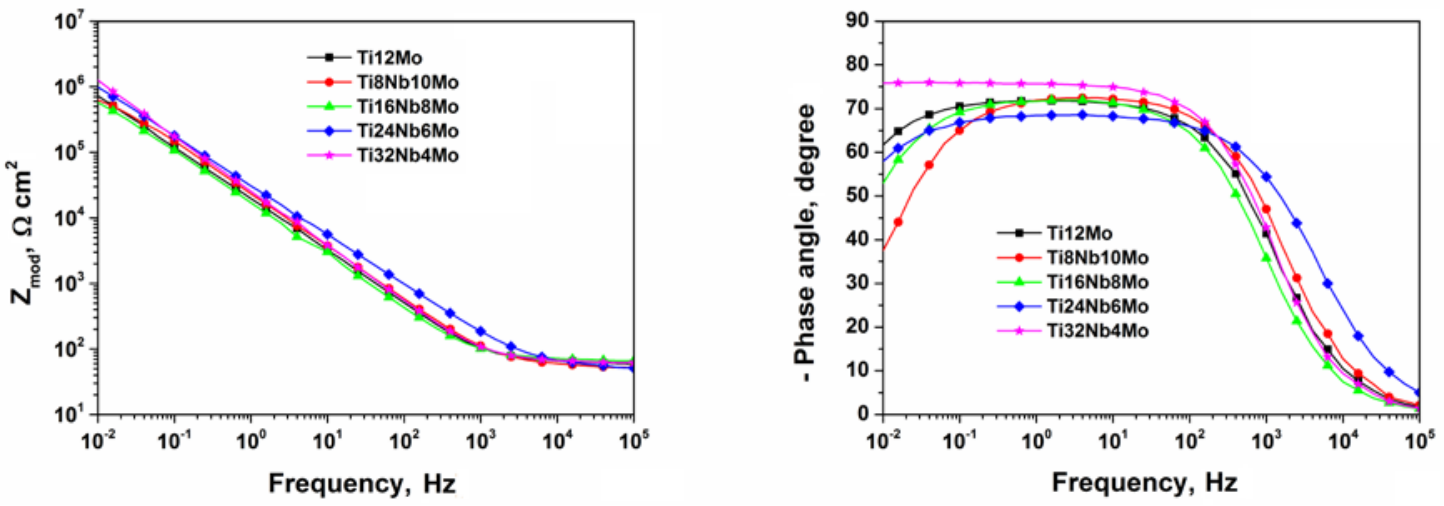

Figure 5.

Bode spectra for Ti12Mo and Ti-Mo-Nb alloys after $1 \mathrm{~h}$ in naturally aerated $0.9 \mathrm{wt} \% \mathrm{NaCl}$ solution at $25{ }^{\circ} \mathrm{C}$, measured at $E_{\text {corr. }}$. Measured (discrete points) and fitted (solid lines) data. 

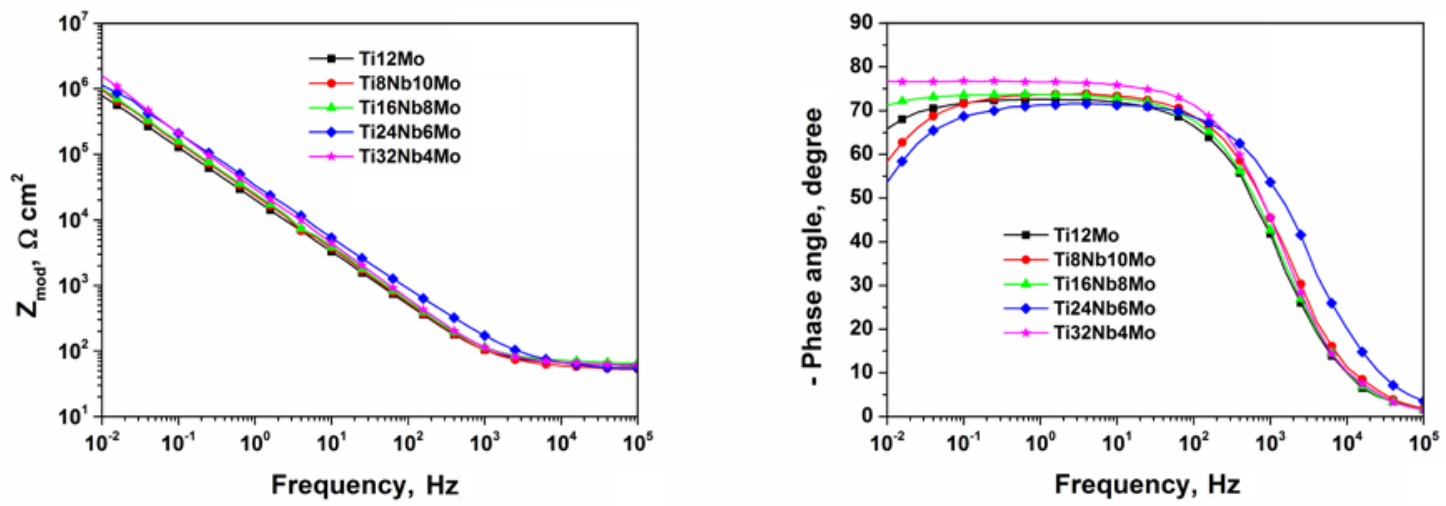

\section{Figure 6.}

Bode spectra for Ti12Mo and Ti-Mo-Nb alloys after $24 \mathrm{~h}$ in naturally aerated $0.9 \mathrm{wt} \% \mathrm{NaCl}$ solution at $25{ }^{\circ} \mathrm{C}$, measured at $E_{\text {corr. }}$. Measured (discrete points) and fitted (solid lines) data.

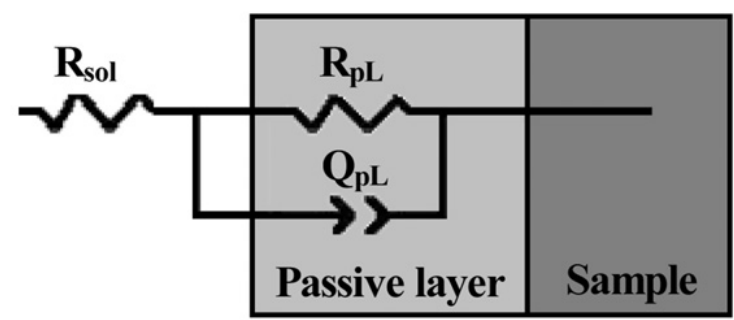

\section{Figure 7.}

Equivalent circuit (EC) used to analyze the impedance spectra.

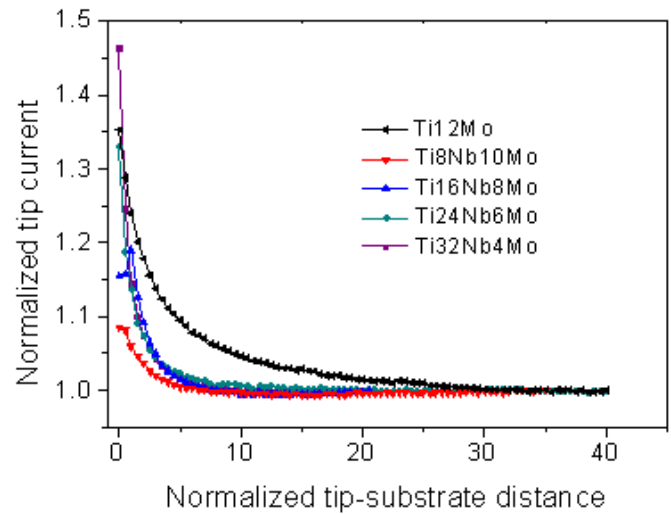

Figure 8.

Typical z-approach normalized curves measured above Ti12Mo and Ti-Nb-Mo alloys during immersion in $0.5 \mathrm{mM}$ ferrocene-methanol $+0.9 \mathrm{wt} \% \mathrm{NaCl}$ solution at ambient temperature. The samples were left unbiased at their corresponding $E_{\text {corr. }}$ Tip potential: $+0.46 \mathrm{~V}$ sce. 

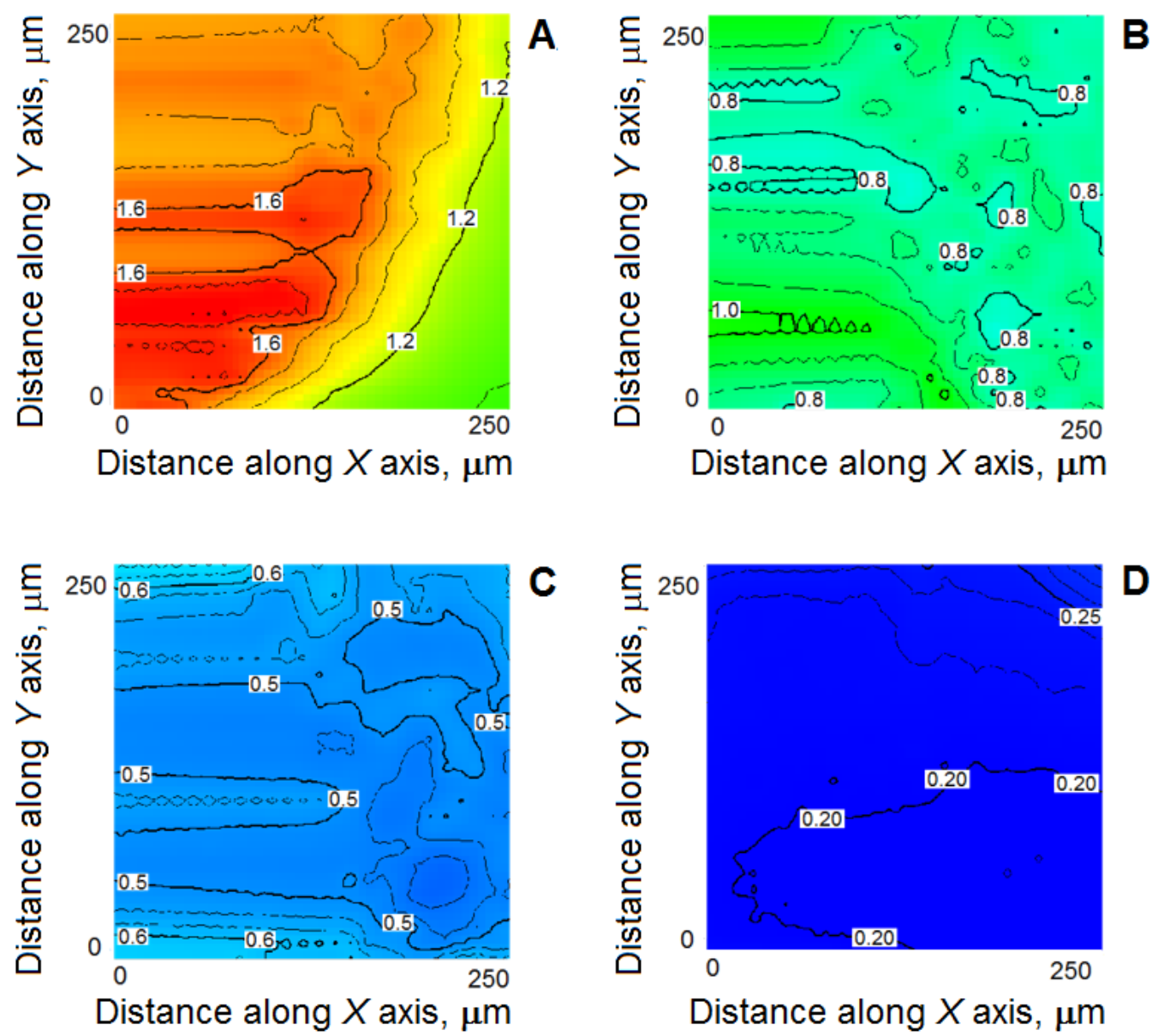

i / ílim

\subsection{0 .61 .01 .41 .8}

\section{Figure 9.}

SECM images of the Ti12Mo surface while (A) left at its spontaneous OCP, and biased at (B) -0.54 , (C) -0.24 , and (D) $+0.16 \mathrm{~V}_{\mathrm{SCE}}$ during immersion in $0.5 \mathrm{mM}$ ferrocene-methanol $+0.9 \mathrm{wt} \% \mathrm{NaCl}$ solution at ambient temperature. Tip to substrate distance: $10 \mu \mathrm{m}$. Tip potential: $+0.46 \mathrm{~V}$ sce. Scan rate: $30 \mu \mathrm{m} \mathrm{s}^{-1}$. 


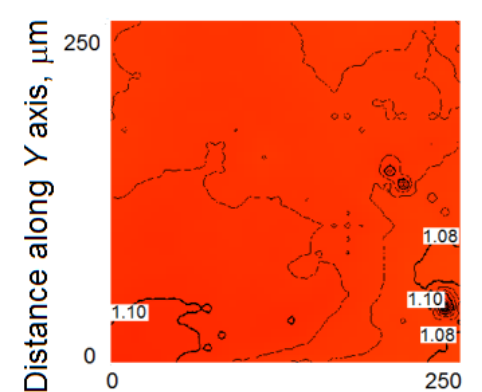

Distance along $X$ axis, $\mu \mathrm{m}$

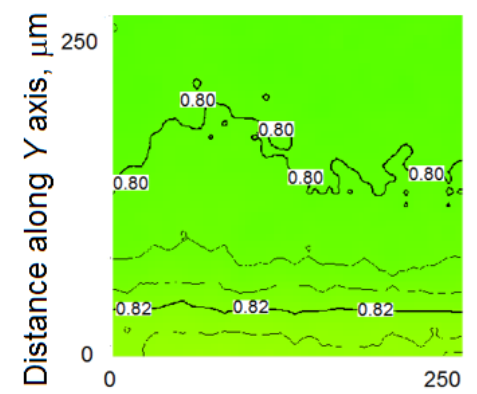

Distance along $X$ axis, $\mu \mathrm{m}$

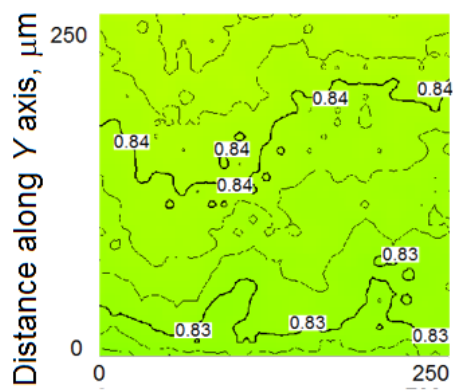

Distance along $X$ axis, $\mu \mathrm{m}$

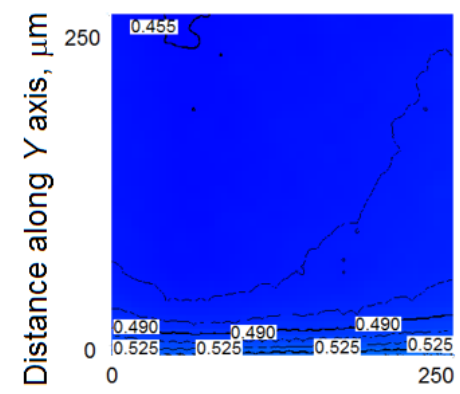

Distance along $X$ axis, $\mu \mathrm{m}$

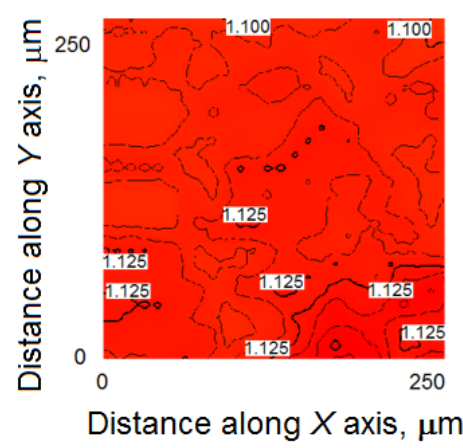

A

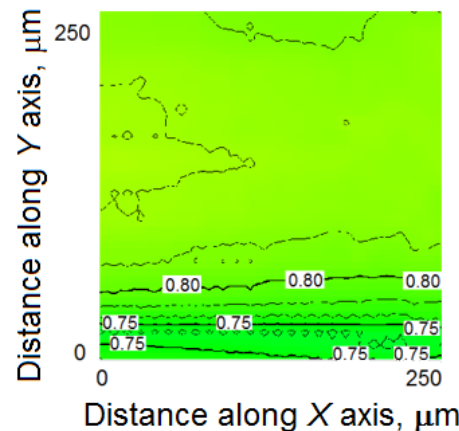

B

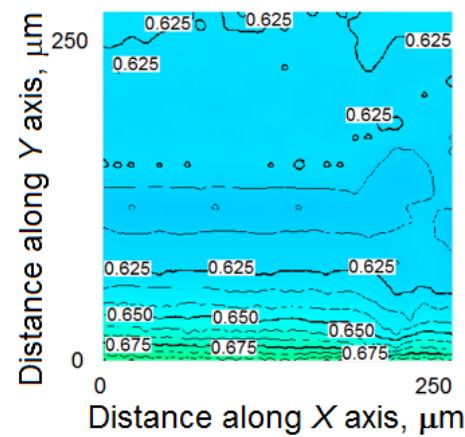

C

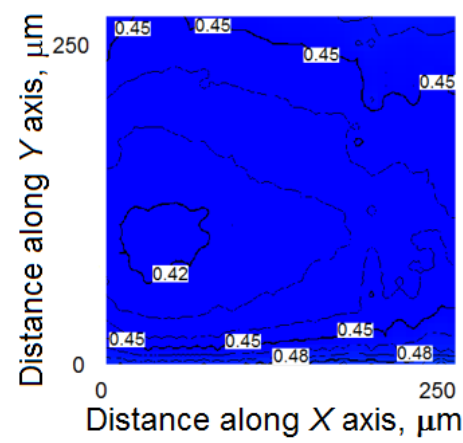

D

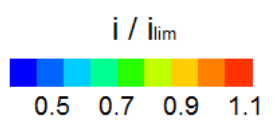

Figure 10.

SECM images of the Ti8Nb10Mo (left) and Ti16Nb8Mo (right) surfaces while (A) left at its spontaneous OCP, and biased at (B) -0.54 , (C) -0.24 , and (D) +0.16 V SCE during immersion in 0.5 $\mathrm{mM}$ ferrocene-methanol $+0.9 \mathrm{wt} \% \mathrm{NaCl}$ solution at ambient temperature. Tip to substrate distance: $10 \mu \mathrm{m}$. Tip potential: +0.46 Vsce. Scan rate: $30 \mu \mathrm{m} \mathrm{s}^{-1}$. 

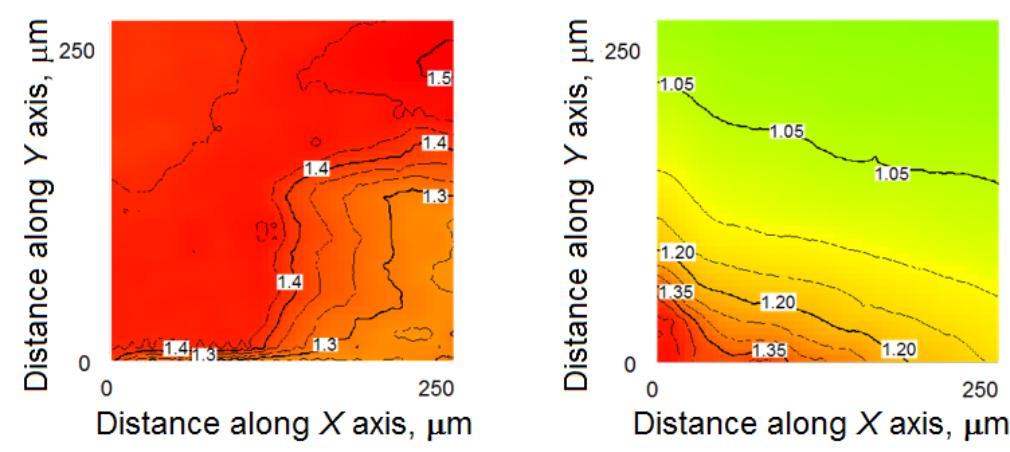

A
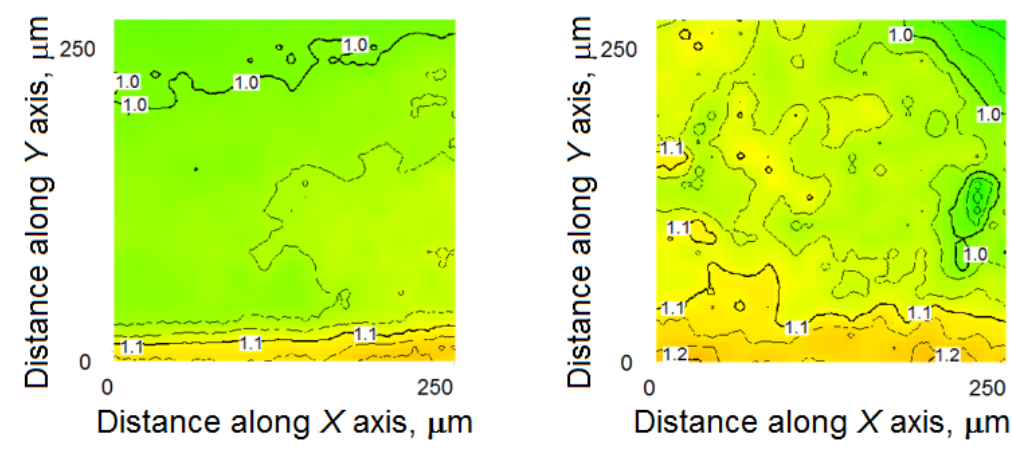

B
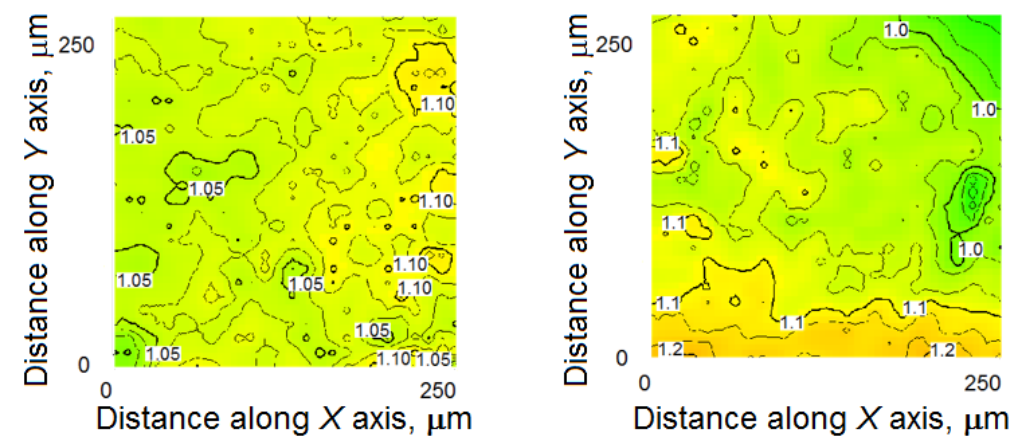

C
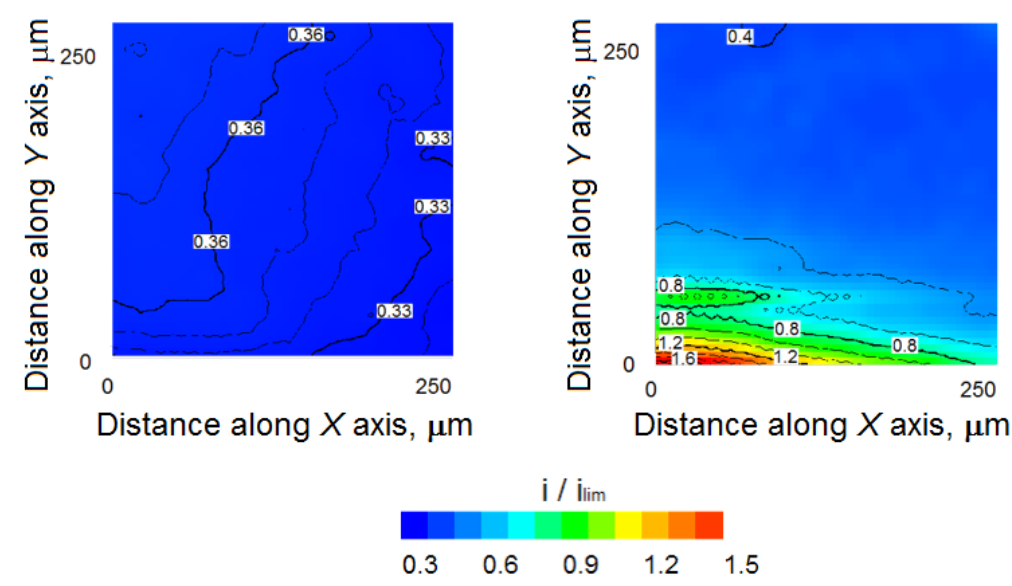

Figure 11.

SECM images of the Ti16Nb6Mo (left) and Ti32Nb4Mo (right) surfaces while (A) left at its spontaneous OCP, and biased at (B) -0.54 , (C) -0.24 , and (D) +0.16 V SCE during immersion in 0.5 $\mathrm{mM}$ ferrocene-methanol $+0.9 \mathrm{wt} \% \mathrm{NaCl}$ solution at ambient temperature. Tip to substrate distance: $10 \mu \mathrm{m}$. Tip potential: +0.46 Vsce. Scan rate: $30 \mu \mathrm{m} \mathrm{s}^{-1}$. 